\title{
SABERES INDÍGENAS NA ESCOLA
}

\author{
Professores Xerente \\ Celso Kazamrĩ \\ Sinval Waĩkazate \\ Carmelita Curtidi Xerente \\ Noemi Waktadi Xerente \\ Vanda Brudi Xerente \\ Afonso Tĩ̃kwa Xerente \\ Roberto Sipkuze Xerente \\ Agripino Wakuke \\ Arlindo Wdêkruwe Xerente \\ Helena Krukwanẽ Xerente \\ Paulo César Kuhânĩpi Xerente \\ Armando Sõpre Xerente \\ Jurandi Souza Xerente \\ Valci Sinã \\ Valteir Tpêkru Xerente \\ Manoel Sirnãrê Xerente \\ Silvino Sirnãwẽ Xerente \\ Rogério Srõne Xerente
}

\section{RESUMO}

Os Akwẽ aprendem a respeitar os outros e a natureza desde muito cedo, quando ainda são criança. Esses ensinamentos, bem como os ensinamentos sobre o modo de vida Akwẽ são transmitidos pelos nossos pais, avós, tios e outros parentes. Durante o primeiro ano da Ação 'Saberes Indígenas na Escola', desenvolvemos duas pesquisas, uma primeira sobre parentesco e clãs e uma segunda, sobre o ciclo de vida da criança Akwẽ. Este segundo tema foi mais explorado por nós. Dividimos as pesquisas sobre o ciclo de vida da criança Akwẽ considerando as diferentes fases da vida da criança. Achamos que a vida da criança começa na gravidez, incluindo resguardo que deve ser feito pelos pais durante a gravidez da mãe; a terceira fase é a do nascimento, seguida do resguardo feito após o nascimento da criança; depois vem a fase de nomeação da criança, seguida do casamento e do término do ciclo de vida da criança, que acontece por volta dos 40 
anos, quando ela deixa de ser considerada criança. É assim na cultura Akwẽ.

PALAVRAS-CHAVE: Povo Akwẽ Xerente. Clã. Parentesco. Ciclo de vida da criança.

\section{ABSTRACT}

The Akwẽ learn to respect others and nature from an early age, when a child. These teachings and the teachings on Akwẽ way of life are transmitted by our parents, grandparents, uncles and other relatives. During the first year of Action Indigenous Knowledge in school, we developed two surveys, a first on kinship and clan and a second on the Akwẽ child's life cycle. This second theme was further explored by us. We share research on the child's life Akwẽ considering the different stages of a child's life. We think the child's life begins in pregnancy, including guard is to be done by the parents during the mother's pregnancy; the third phase is the birth, then the guard made after the child's birth; then comes the child's appointment phase, then marriage and the end of the child's life cycle, which occurs at about 40 years, when it ceases to be considered child. This is how is the Akwẽ culture.

KEYWORDS: People Akwẽ Xerente. Clan. Kinship. Child life.

Como teve grande impasse no início deste projeto, por falta de engajamento e compreensão por parte da equipe componente, demorou-se a compreender do que se tratava esse projeto. Por isso as articulações e os engajamentos no processo de desenvolvimento nas pesquisas demoraram.

Mas, conforme os encontros foram acontecendo, a equipe foi se articulando, e em cada encontro que acontecia nós íamos abrindo a roda de conversa e orientação, sobre proposta do tema pesquisado. Por isso, nos dias 26 e 27 de março de 2014, recolhemos a primeira pesquisa sobre parentesco e clãs, com título do trabalho "Modo próprio de tratamento do povo Akwẽ".

A seguir mostramõs as tabelas com os nomes.

Pesquisa sobre parentesco e clãs (em andamento). 
Trabalhos relacionados à formação de professores indígenas.

Data das pesquisas: dias 26 e 28 de março de 2014.

Senhor pesquisado: Paulo Simnã

Aldeia: Suprazapdo, Sangrador.

Modo de tratamento do povo AKWẼ:

\begin{tabular}{|c|c|c|c|c|c|c|c|c|c|}
\hline ĨNATKÂ & & Ambâ & pikõ & $\begin{array}{c}\text { SIKU- } \\
\text { TÕRPARI }\end{array}$ & ĩmmã & & ambâ & pikõ & Sikutõrpari \\
\hline & & ĩwamtrẽ-kwa & $\begin{array}{c}\text { ĩwamtrẽ- } \\
\text {-kwa }\end{array}$ & & & & $\begin{array}{c}\text { ĩwamtrẽ- } \\
\text {-kwa }\end{array}$ & $\begin{array}{c}\text { ĩwamtrẽ- } \\
\text {-kwa }\end{array}$ & \\
\hline \multirow[t]{6}{*}{$\begin{array}{c}\text { ĨZE- } \\
\text { PARKWA }\end{array}$} & $\tilde{I} P N A \tilde{A}$ & ĨNATKÂ & ĩnatkâ & WANÃDI & $\begin{array}{c}\text { ĩp- } \\
\text { tokwa }\end{array}$ & ĩpnã & ĩmmã & ĩmmã & Wammãdi \\
\hline & ĨSDEKWA & ĨNATKÂ & ĩnatkâ & WANÃDI & & ĩsdekwa & ĩmmã & ĩmmã & Wammãdi \\
\hline & ĨHITBRE & NÕKRÊKWA & nõkrêkwa & $\begin{array}{c}\text { wanõkrê- } \\
\text { mzukwa- } \\
\text { iti }\end{array}$ & & îhidba & îtbê & itbê & Watbêkwapti \\
\hline & ĨPTOKWA & ĨKRDA & îkrda & $\begin{array}{c}\text { wahîkr- } \\
\text { tadi }\end{array}$ & & ĩptokwa & îkrda & îkrda & Wahĩkrtadi \\
\hline & $\begin{array}{c}\text { ĨSE- } \\
\text { PARKWA }\end{array}$ & ĨKRDA & îkrda & $\begin{array}{c}\text { wahĩkr- } \\
\text { tadi }\end{array}$ & & $\begin{array}{c}\text { ĩse- } \\
\text { parkwa }\end{array}$ & îkrda & ĩkrda & Wahĩkrtadi \\
\hline & & ĩwamtrẽze & ĩwamtrẽze & & & & $\begin{array}{c}\text { ĩwam- } \\
\text { trẽze }\end{array}$ & $\begin{array}{c}\text { ĩwam- } \\
\text { trẽze }\end{array}$ & \\
\hline \multirow[t]{6}{*}{$\begin{array}{c}\text { WA } \\
\text { AMBÂA }\end{array}$} & $\begin{array}{l}\text { ĨPNÃ } \\
\text { MRÕ }\end{array}$ & & asimhi & $\begin{array}{c}\text { wanĩm- } \\
\text { nĩpkwaiti }\end{array}$ & $\begin{array}{l}\text { WA } \\
\text { PIKÕ }\end{array}$ & Ĩpnã mrõ & snĩkmõ & & $\begin{array}{c}\text { Wasdi- } \\
\text { kumkwapti }\end{array}$ \\
\hline & $\begin{array}{c}\text { ĨSDEKWA } \\
\text { MRÕ }\end{array}$ & & asimhi & $\begin{array}{c}\text { wanĩm- } \\
\text { nĩpkwaiti }\end{array}$ & & $\begin{array}{c}\text { Ĩsdekwa } \\
\text { mrõ }\end{array}$ & snĩkmõ & & $\begin{array}{c}\text { Wasdi- } \\
\text { kumkwapti }\end{array}$ \\
\hline & $\begin{array}{c}\text { ĨHIDBA } \\
\text { MRÕ }\end{array}$ & ĨZAKMÕ & & $\begin{array}{c}\text { wa- } \\
\text { zakũmdi }\end{array}$ & & $\begin{array}{c}\text { Ĩhitbre } \\
\text { mrõ }\end{array}$ & & asahi & $\begin{array}{c}\text { Was- } \\
\text { sanĩkwapti }\end{array}$ \\
\hline & Ĩpnã kra & bremĩ & bakrnõ & $\begin{array}{c}\text { wa- } \\
\text { krawap- } \\
\text { temdi }\end{array}$ & & Ĩpnã kra & bremi & baknõ & $\begin{array}{c}\text { Wakrawap- } \\
\text { temdi }\end{array}$ \\
\hline & $\begin{array}{c}\text { Ĩsdekwa } \\
\text { kra }\end{array}$ & bremĩ & bakrnõ & $\begin{array}{c}\text { wa- } \\
\text { krawap- } \\
\text { temdi }\end{array}$ & & $\begin{array}{c}\text { Ĩsdekwa } \\
\text { kra }\end{array}$ & bremĩ & baknõ & $\begin{array}{c}\text { Wakrawap- } \\
\text { temdi }\end{array}$ \\
\hline & Ĩhidba kra & krêmzu & krêmzu & $\begin{array}{l}\text { wanĩm- } \\
\text { nõkrê- } \\
\text { mzuiti }\end{array}$ & & $\begin{array}{c}\text { Ĩhitbre } \\
\text { kra }\end{array}$ & abâdi & pikõiti & Wanĩhdudi \\
\hline
\end{tabular}

Através desta pesquisa tivemos uma noção de que foi, a partir da descoberta do fogo, que começaram a surgir os clãs, pois a história diz que a onça trouxe o fogo consigo. E sua pintura foi adotada como um símbolo de um clã que é Kuzâ. Hoje compreendemos que 
as pinturas têm referências à natureza: Kuzâa, Kbazi Krito, Wahirê, Krozake, Krẽprehi.

"Ahâmre tô nãrkwa kramẽ za sisnã mrõ." (Simnã).

Tanẽ hawi wat samãr waihuk tô dasiwawi zem hawi za dasiwaze.

Daptokwa siwawizem hawi kãtô daseparkwa tdêkwa siwawi zem hawi, waza isanãmr ze wat waihuk. Smĩsi mãt ĩrtĩkwanĩ. Wat kmã ĩsimãzus, mãr wap ĩmmã kra waza kmã ĩsipnã, ĩsdekwa, tanẽkõwa îhidba. Tanẽkõdi nõkrêkwa akra snĩ ambâ waza dure nõkrêkwa nã wamtẽ, are pikõ waza inatkâ nã wamtẽ. Ãre mãr wa? Tô dasiwawizem havi, waza nãrkwa nõri wat sazẽi pês, are wasiwadi, waptowai siwawi zem hawi kwasiwa kwa nõmr. Tô wasiwazem snã dure, tôwa aimuhi snã. Wasiwa waza wasis sakran.waza wasihân,dasipnã nẽ, tô wahidba nẽ.

No dia 26 de junho de 2014, às 9hs da manhã, ocorreu a reunião no Núcleo de Licenciatura Intercultural de Formação Superior para Professores Indígenas, na oca, na Universidade Federal de Goiás, com seis professores Akwẽ participantes da Ação 'Saberes Indígenas na Escola', e mais três professores não indígenas.

Começamos a nos reunir dia 11 de janeiro de 2014, com alguns professores que estão participando dos 'Saberes Indígenas na Escola'. Nós nos reuníamos várias vezes com os professores. $\mathrm{Na}$ reunião foram discutidas as pesquisas que todos irão pesquisar. A pesquisa é sobre os parentescos e clãs.

Em janeiro de dois mil e quatorze, foi feita a pesquisa sobre parentesco e, na sequência, no mês de fevereiro, também foi feita a pesquisa sobre os clãs. Nós começamos sobre os parentescos, e depois sobre os clãs. Começamos a registrar todas as escritas sobre a nossa cultura. Todos os professores escreveram sobre o tema proporcionado sobre os clãs, e depois apresentaram para os seus colegas de trabalhos.

O nome 'saberes indígenas' já disse que nós indígenas aprendemos muitas coisas sobre a nossa cultura no ciclo da nossa família, pais, avô, avó, bem como ao redor do fogo pela manhã, contando as histórias, ensinando para as crianças saber respeitar o próximo e a lei da natureza. Na nossa cultura acreditamos que, só 
quando tocamos nas coisas, ouvimos sobre a nossa cultura. Segue o momento que a crianças Akwẽ começam a praticar, exemplo: a pintura corporal - a criança Akwẽ não nasce sabendo. Elas começam a ver outros pintando, mas um dia a mãe ou o pai ou tio começam ensinar para as crianças Akwẽ, para elas testarem de pintar o colega delas.

A segunda reunião foi no dia $\mathbf{0 8}$ de março, segunda-feira. Foi feito reforço sobre as pesquisas feitas pelos professores, e a terceira reunião foi só para receber os trabalhos dos professores Akwẽ, que eles fizeram as pesquisas. Alguns professores entregaram, mas outros não, para os coordenadores, como exemplo, o professor Valci Sinã fez em sua escola, com os alunos na Escola Indígena Waikarnãse. Os professores fizeram práticas com as crianças daquela escola, mostraram para as crianças a pintura corporal, pintando as crianças com seus próprios clãs, e outras pinturas como casamento. Isso foi com anciã daquela aldeia praticando para as crianças, que viram com seus próprios olhos. Ponto positivo que todos os professores participaram, ponto negativo foi a dificuldade de a gente se reunir no local, de nos comunicarmos com os outros colegas professores.

A proposta sobre saberes foi muito importante, porque é voltada para nossa cultura. Parece que alguém foi na aldeia para perguntar sobre a vida dos Akwẽ. Foi um projeto bem pensado, que os indígenas irão escrever para documentar e guardar escrita. Com esse projeto vamos escrever um livro sobre como começamos a ensinar para as crianças Akwẽ. O ciclo de vida das crianças começa a partir da mãe quando fica grávida. Dali começa a se mexer na barriga da mãe, conversa com a mãe. Depois que nasce a criança começa a conversar com a mãe ou outros que são da família, dando sorriso para os parentes. Isso na oralidade, porque os pais ensinam para os filhos, até mais ou menos 02 anos. A partir daí eles continuam até 06 anos de idade, quando começam a praticar como pintar os colegas, ou fazer artesanatos.

A terceira reunião aconteceu no dia 23 de agosto. Nós nos reunimos sobre 'saberes indígenas', na sede da Associação do Procambix, para repassarmos sobre 'saberes indígenas', para os nossos colegas professores que são bolsistas na Ação de 'saberes indígenas na Escola'. Nesse dia chegaram alguns professores para 
pegar informação sobre a reunião em Goiânia, que havia acontecido nos dias 26, 27 e 28 de junho de 2014. O professor Valteir Tpêkru Xerente explanou sobre a reunião em Goiânia. Ele explicou sobre o tema que foi abordado, que foi o ciclo da vida das crianças indígenas Akwẽ, que todas as etnias falaram de suas crianças, como começam, quando começa a vida das crianças de cada povo.

Explicamos que o ciclo da vida das crianças Akwẽ começa quando estão ainda na barriga de sua mãe, quando ainda está na gravidez. Dali começa o ciclo da vida da criança. Valteir disse para cada um que estava presente pesquisar o tema e também explicou como escrever sobre o ciclo das crianças Akwẽ.

No dia 11 de outubro aconteceu outra reunião sobre saberes indígenas, no mesmo local, na sede do Programa de Compensação Ambiental Indígena Xerente, a Procambix, em Tocantínia, pela manhã. Chegaram alguns professores naquele dia para reforçar sobre a escrita sobre o ciclo das crianças Akwẽ, para todos os professores começarem a escrever conforme cada um entendesse para o próximo encontro. Também cada um começaria a pesquisar com o ancião da sua aldeia ou de outra aldeia onde todos os professores têm como pesquisar.

No dia 18 de outubro foi outro encontro, na sede do Programa de Compensação Ambiental Indígena Xerente, a Procambix, com os professores Xerente, para reforçar o tema que nós vínhamos discutindo nos encontros anteriores. Todos os professores que estavam presentes naquele dia tinham perguntado tirando a sua dúvida sobre o tema escolhido, que foi o ciclo da vida das crianças Akwẽ. Todos os professores Xerente que foram em Goiânia explicaram sobre o encontro que aconteceu naquele mês.

Naquele dia também foi falado sobre o trabalho da professora Carmelita Krtidi Xerente, que ela tinha começado a escrever como começa a vida das crianças Akwẽ. Ela escreveu que as crianças Akwẽ começam na beira do fogo quando elas ficam com o pai ou avô. Dali começa a ouvir a história que é contada na beira do fogo. Ela também fez desenho de crianças sentadas na beira do fogo. Isso foi repassado para os professores presentes naquele dia.

Os professores Xerente se reuniram três vezes, para discutirem sobre a Ação 'Saberes indígenas na Escola'. Todos os professores 
participaram dessa ação que a UFG conseguiu para cada povo que está participando. Dali cada povo vai escrever um artigo, ou livro para ser usado nas escolas, como um livro didático para todos os professores que não estão participando da Ação.

O último encontro foi na aldeia Porteira Nrõzawi, com a professora Léia Silva, que explicou sobre a Ação, quando todos tiraram as dúvidas. Ela nos orientou a continuar a escrever sobre o ciclo da vida das crianças Akwẽ e também a pesquisar com os anciãos de sua aldeia e outras aldeias, que irão ajudar na pesquisa de todos os professores que estão envolvidos na Ação 'Saberes Indígenas na Escola'. Cada um deve entregar as pesquisas segundo o tema que foi pesquisado e ser entregue aos coordenadores. 